\title{
Makna Narasi Musik Perkusi Calempong Unggan: Tinjauan Narratology
}

\author{
Hery Budiawan \\ Pendidikan Musik, Fakultas Bahasa dan Seni, Universitas Negeri Jakarta \\ herybudiawan@unj.ac.id \\ Fahmi Marh \\ Seni Musik, Fakultas Seni Pertunjukan, Institut Seni Indonesia Padang Panjang \\ fahmi_marh@yahoo.com
}

\begin{abstract}
Abstrak
Calempong Unggan merupakan musik tradisi Minangkabau dari Nagari Unggan yang mempunyai narasi terbagi menjadi 3 tahapan yaitu intramusikal, ekstramusikal dan perilaku musikal. Ketiga tahapan ini menjadi landasan dalam proses transmisi dan memaknai eksistensinya dalam aktifitas kebudayaan masyarakat. Membicarakan Calempong Unggan maka dalam aktifitas masyarakat sering terkait dengan cerita rakyat yang memberikan nilai sejarah terhadap instrumen perkusi tersebut sehingga hal ini menjadi fokus permasalahan karena posisi cerita rakyat dalam 3 tahapan, yaitu intramusikal, ekstramusikal dan perilaku musikal. Mengadopsi konsep narratology sebagai suatu bidang naratif maka dalam penelitian ini mencoba menggunakan teori dari Rolland Barthes untuk membaca narasi musik tradisi dari rakyat. Narasi-narasi musik calempong ini dibaca sebagai narasi yang naratif, pola-pola narasi untuk pertunjukan calempong yang dipahami dari praktek musik tradisi suatu masyarakat. Untuk pemaknaan maka konsep Nattiez mengenai pemaknaan musik melalui tiga tataran keilmuan untuk menjelaskan pemaknaan. Metode penelitian yang dipergunakan adalah kualitatif jenis narasi yang berfungsi untuk memahami narasi musik melalui musisi atau pemainnya. Baik narasi secara musikal dari komposisi-komposisi calempong yang telah dimainkan maupun narasi non musikal. Jenis data yang digunakan adalah data primer dan data sekunder. Data primer diperoleh dengan membaca komposisi berdasarkan narasi yang diwakili pada judul, serta narasi dari pengalaman musisi dari komposisi. Kemudian wawancara langsung dengan pemain musik calempong, dan narasumber yang berkaitan pertunjukan calempong. Sementara data sekunder diperoleh dari berbagai tulisan, hasil penelitian, foto, dan rekaman audio visual (vcd dan DVD) pertunjukan calempong.Penelitian menunjukkan bahwa masyarakat Unggan mengenal kuanta bunyi yang mempunyai dualisme bunyi sebagai partikel dan gelombang, mempunyai erat dengan filosofi masyarakat tentang sistem kehidupan sehingga mengkontruksi pada sebuah makna keseimbangan dalam kehidupan.
\end{abstract}

Keyword: Musik Perkusi Calempong, Narasi, Narratology

Calempong Unggan is a traditional Minangkabau music from Nagari Unggan which has a narrative divided into 3 stages, namely intramusical, extramusical and musical behavior. These three stages become the basis for the transmission process and interpret their existence in the cultural activities of society. Talking about Calempong Unggan, in community activities it is often related to folklore which gives historical value to these percussion instruments so that this becomes the focus of the 
problem because the position of folklore is in 3 stages, namely intramusical, extramusical and musical behavior. Adopting the concept of narratology as a narrative field, this research tries to use the theory of Rolland Barthes to read traditional music narratives from the people. The narratives of calempong music are read as narrative narratives, narrative patterns for calempong performances that are understood from the traditional music practice of a society. For meaning, Nattiez's concept of the meaning of music goes through three scientific levels to explain the meaning. The research method used is a qualitative type of narrative which serves to understand the narrative of music through the musicians or the players. Both musical narratives from Calempong compositions that have been played and non-musical narratives. The types of data used are primary data and secondary data. Primary data is obtained by reading the composition based on the narrative represented in the title, as well as the narrative of the musician's experience of the composition. Then direct interviews with Calempong musicians, and other sources related to the Calempong performance. Meanwhile, secondary data were obtained from various writings, research results, photos, and audio-visual recordings (vcd and DVD) of Calempong performances. Research shows that the Unggan community recognizes sound quanta which has the dualism of sound as particles and waves, and is closely related to society's philosophy of living systems. thus constructing a meaning of balance in life

\section{A. Pendahuluan}

Calempong Unggan adalah musik perkusi tradisional Minangkabau yang berasal dari Nagari Unggan kecamatan Sumpur Kudus kabupaten Muaro Sijunjung di wilayah pegunungan Sumatera Barat. Calempong Unggan, musik yang memiliki narasi kehidupanya, mulai dari "proses kelahirannya sebagai musik", "kepercayaan yang melekat pada musik", sampai pada "repertoar atau komposisi musiknya sebagai ruang komunikasi” penciptaan musik (komposer) dengan musisi dan audiensnya dalam permainan musik. Keraf (2001:137) menjelaskan bahwa Narasi merupakan suatu bentuk wacana yang berusaha mengisahkan suatu kejadian seolah-olah pembaca melihat atau mengalami sendiri peristiwa tersebut.
Ketiga narasi tersebut merupakan narasi sugestif, sebuah jenis narasi di dalamnya terdapat kisah rekaan, khayalan, atau imajinasi dari pengarang. Narasi ini bersifat fiktif yang melibatkan imajinasi dimana tujuannya adalah kesan terhadap peristiwa yang dikisahkan oleh musik rakyat, sekaligus digunakan sebagai bahasa naratif-nya akan penulis narasikan secara umum. Naratif berbeda pengertiannya dengan narasi dan stori, naratif adalah bentuk bahasa atau bahasa yang dipakai, sedangkan narasi adalah kisah atau cerita yang dibawakan oleh bentuk bahasa naratif, kemudian stori adalah konten atau isi yang bisa dibicarakan dengan naratif. .

Naratif musik calempong suatu kajian makna narasi musik perkusi tradisional berkaitan dengan masalah hubungan tingkatan naratif, narasi, dan story (isi) "kehidupan musik calempong", atau lebih 
tepatnya melihat narasi satu "kehidupan" musik tradisional Minangkabau dengan pemaknaan yang berbeda. Permasalahan dalam aktifitas kebudayaan masyarakat, seringkali terdapat penilaian bahwa posisi musik tradisi sering dianggap sebagai imajinasi, patologi sehingga memberikan dampak terhadap kesimpangsiuran informasi, oleh sebab itu langkah yang tepat apabila kehidupan musik tradisi dikontruksi dalam wujud narasi sesuai naratif agar tidak dianggap sebagai patologi, sehingga mampu dikaji dan memberikan kontribusi dalam pengembangan musik tradisi. Kajian ini didasarkan pada narasi musik dari asal mula penciptaan musik sampai pada kehidupannya hari ini di Unggan. Melalui narratology, kajian ini berusaha membuat naratif musik sebagai upaya menarasikan musik yang sebenarnya "bersumber dari alam", "menjadi suatu kepercayaan", dan "permainan musik yang dimaknai" yang mana maknanya sama sekali berbeda yang akan dibaca oleh pembacanya

\section{Narratollogy}

Naratologi dimulai dari tahun enam puluhan dari Barthes (1966), Bremond (19641966), Greimas (1966), dan Todorov (19691970), (Gerald Prince, 1991: 553). Naratologi adalah ilmu tentang teori naratif yang terdiri dari dua relasi, distribusional dan integrasional (Barthes, 1990: 242). Gentte (1972) mendefenisikan istilah naratif sebagai model (hubungan seorang narator) daripada objek (adalah presentasi event) atau peristiwa, dan mengeksplorasi apa yang merupakan wilayah istimewa dari naratif yaitu "wacana" dan bukan "story" (cerita), (Gerald Prince, 1991: 553). Sunardi juga menyebutkan dalam "Semiotika Negativa" bahwa naratologi ilmu tentang teori naratif, naratif dilihat dari perspektif wacana, pengembangan Barthes dari linguistik wacana, grama wacana, dan lingustik kedua (Sunardi, 2002: 237). Naratif tidak hanya hanya persoalan berpindah dari satu kata dengan kata yang lain tapi juga berpindah level ke level yang berikutnya (Barthes, 1990: 87). Untuk menemukannya, maka perlu beralih dari level pertama ke level berikutnya. Langkah seperti itu menurut Barthes, dalam naratif bergerak dari level fungsi, level aksi, dan level narasional, yang masing masingnya saling terkait dan tidak dapat dipisahkan dalam membangun struktur naratif (Barthes, 1990: 243).

\section{Nattiez}

Pemaknaan musik etnis nusantara merupakan sebuah peristiwa yang menarik dalam mengkontruksi asal-usul serta perkembangannya dari jaman ke jaman, konsep naratollogy yang dikemukakan oleh Barthes, Todorof mempunyai prinsip kesamaan dengan pembagian wilayah naratollogy Jan Alber (2010). Kathryn Hayles 
(2008) bahwa pemaknaan tidak bisa lepas dari wilayah semiotika baik tata bahasa, kode, superstruktur sehingga seringkali konsep ini sejajar dengan intepretasi musikal yang dikembangkan oleh Nattiez (1990) mengenai analisis intramusikal, eskstramusikal dan perilaku musikal atau tahapan ini digunakan untuk menjelaskan sebuah cerita dari sebuah obyek secara naratif.

\section{B. Metode Penelitian}

Metode penelitian yang dipergunakan adalah kualitatif jenis naratif, Cresswell (2008) istilah naratif berasal dari kata kerja "menceritakan" atau "mengatakan" (sebagai cerita) dalam detail atau rinci. Dalam desain penelitian naratif, peneliti mendeskripsikan kehidupan dan individu, mengumpulkan dan menceritakan cerita mengenai kehidupan orang, dan menulis naratif dari pengalaman individu. Sebagai bentuk yang jelas dari penelitian kualitatif, sebuah naratif biasanya fokus pada penelitian satu orang mendapatkan data dari pengumpulan cerita, melaporkan pengalaman individu, dan mendiskusikan makna dari pengalaman-pengalaman tersebut untuk individu.

Metode ini untuk memahami narasi musik melalui cerita turun-temurun musisi atau pemainnya baik langsung kepada pelaku yang masih hidup, maupun melalui cerita dari garis keturunan pelaku langsung semenjak tahun 1942-2020. Baik narasi secara musikal dari komposisi-komposisi calempong yang telah dimainkan maupun narasi non musikal. Jenis data yang digunakan adalah data primer dan data sekunder. Data primer diperoleh dengan membaca komposisi berdasarkan narasi yang diwakil pada judul, serta narasi dari pengalaman musisi dari komposisi. Kemudian wawancara langsung dengan pemain musik calempong, dan narasumber yang berkaitan dengan narasi musik calempong. Sementara data sekunder diperoleh dari berbagai tulisan, hasil penelitian, foto, dan rekaman audio visual (ved dan DVD) pertunjukan calempong.

\section{Hasil dan Pembahasan}

\section{Narasi musik}

Pertama, narasi tentang proses kelahiran musik Calempong Unggan dari orang pertama (nenek moyang masyarakat Unggan) berdasarkan cerita musisi kelahiran 1942. Kelahiran musik Calempong Unggan berasal dari bagian peristiwa pengalaman perjuangan hidup nenek moyang masyarakat Unggan. Sebagian dari pengalaman itu adalah terciptanya musik yang prosesnya persis sama dengan mimesis (bunyi sebagai representasi) dimana pelaku sebagai orang pertama meniru pendengaran bunyi dari dari dunia ide. Dimana bunyi yang berasal dari alam, dialami 
secara auditori, kemudian titik bunyi yang paling berkesan menjelma ke seluruh sel-sel diri nenek moyang masyarakat Unggan. Jelmaan bunyi yang paling berkesan itu dipresentasikannya kembali menjadi musik ke dalam frekuensi nada yang khusus pada kelompok alat-alat musik perkusi yaitu Calempong Unggan. Yang pada awalnya alat-alat musik tersebut hanya berupa bilahan kayu yang bernada. Namun dengan bergeraknya waktu seiring dengan perkembangan teknologi alat-alat yang pada awalnya kayu bertransformasi menjadi alat perungu.

Kedua, narasi kepercayaan masyarakat yang melekat pada musik Calempong Unggan yang diyakini secara turun-temurun oleh masyarakat Unggan. Kepercayaan itu adalah: larangan membunyikan musik dimasa padi bercocok tanam padi. Dipercayai oleh masyarakat Unggan bahwa: apabila musik dimainkan pada masa itu, maka padi akan gagal panen karena seluruh isi padi akan dimakan oleh makhluk gaib yang mana makhluk gaib itu mereka sebut dengan istilah “Urang Bunian”. Musik perkusi Calempong Unggan hanya boleh dimainkan (berbunyi) setelah panen, yang mana masa itu disebut sebagai masa "baralek". Rentang masa baralek ini peristiwa musik yang terjadi setelah panen sampai pada masa kembali menanam padi.

Ketiga, narasi repertoar dan sistem musik Calempong Unggan sebagai ruang komunikasi pencipta, musisi dan masyarakat. Repertoar musik itu terdiri dari lima segmen judul: Pertama, repertoar musik yang merupakan jelmaan alam sebagai kawasan berpenghuni yang berupa judul nama daerah yaitu: Pararakan Kuntu, Ludai, Silampam, Tanjuang Bolik, Rantau Subayang, Singingi, Pangkalan Sarai. Kedua, repetor musik yang jelmaan dari binatang berupajudul nama binatang yaitu: Siamang Tagogau, Tupai Bagoluik, Ramo-ramo Tobang Tenggi. Ketiga, repertoar musik yang jelmaan kontak fisik manusia dengan alam seperti, tertusuk serat batang kayu, berperahu, berupa judul yaitu: Batang Tarunjam, Ncang dayuang Mudiak, Ncang Dayuang Ilia. Keempat, judul repertoar musik yang jelmaan dari orang tua mecari buah berupa judul yaitu: Urang Tuo Mancari Pauah. Kelima, yang jelmaan dari prosesi adat berupa judul yaitu: Batimbang Baju.

\section{Level Fungsi}

Fungsi memiliki dua kelas relasi yaitu distribusional dan integrasional: Relasi distribusional, relasi ide musik komposer, instrumen, pemain, tempat-tempat pertunjukan dan penonton sebagai penyalur kisah pada level yang sama, sedangkan integrasional bunyi komposisi-komposisi calempong relasi kisah antar level narasi pertama dengan level yang lebih tinggi. Relasi ini untuk membedakan level deskripsi pada 
level pertama dan menempatkan level-level dalam perspektif (integrasional) dari materi atau kisah yang akan dideskripsikan lalu disusun secara hirarki (Barthes, 1990: 242, 244). Fungsi distribusional adalah perluasan keyakinan Propp dan Bremond bahwa distribusional itulah yang sebagai fungsi. "Fungsi" digunakan pada "unit-unit distribusional" walaupun unit-unit lain juga fungsional (Barthes, 1990: 242). Misalnya: "aksi menirukan bunyi-bunyi alam sekitar dengan calempong memiliki hubungan dengan momen ketika bunyi itu digunakan sebagai musik", tindakan "memainkan alat tersebut memiliki hubungan dengan menyimpan alat musik", "masuknya makhluk gaib ke dalam musik memiliki hubungan dengan kepercayaan masyarakatnya Unggan terhadap musik". Fungsi distribusional mengerakkan maju, kelas utama fungsi: fungsi pokok, katalisator indeks dan informan narasi musik. Tetapi kadang-kadang dalam konstribusi makna yang lebih penting malah terletak pada indeksikal.

Fungsi relasi integrasional terdiri atas "petunjuk-petunjuk" dalam pengertian yang luas, relasi antar level dengan level diatasnya (Barthes, 1990: 245). Maka unit integrasional tidak mengacu pada tindakan konsekuensi tetapi pada suatu konsep makna cerita meskipun baru akan jelas pada level yang berikutnya. Makna cerita itu berupa petunjuk psikologis pada karakter-karakter yaitu datadata tentang identitas, catatan-catatan tentang situasi, untuk menyatukan bahasa naratif. Hubungan satu unit integrasional dengan pasangannya petunjuk mengacu pada satu petanda yang sama dan peristiwa tidak lagi berurutan. Petunjuk mengacu pada petanda, bukan pada tindakan. Untuk memahami apa yang ditunjuk baru hanya bisa difahami pada level yang lebih tinggi (Barthes, 1990: 242). Unit fungsi dan petunjuk gunanya untuk mengelompokkan naratif. Beberapa naratif sangat fungsional sedangkan yang lainnya bersifat indeksikal yang sarat dengan petunjuk (Barthes, 1990: 247).

Jika kembali pada fungsi, beberapa kelas utama unitnya berfungsi sebagai titik engsel naratif sedangkan unit yang lain berfungsi sebagai pengisi ruang naratif yang berbeda dengan titik engsel. Pertama "fungsi pokok" (cardinal fuctions), "fungsi katalisator" dan, "fungsi indeksikal" dan informan. Fungsi pokok, momen-momen dalam naratif yang terbuka terhadap segala kemungkinan yang menentukan alur naratif dan kunci untuk mengetahui struktur naratif. Level fungsi sebagai penataan konsekusi (urutan) dan konsekuensi (akibat) unit-unit untuk meringkaskan sesuatu kisah (Barthes, 1990: 250). Sedangkan fungsi katalisator, berperan dalam membentuk pesan dalam istilah Jakobson fungsi tetapnya mempermainkan 
suasana atau perasaan. Fungsinya katalisator, mempercepat, menunda, memberikan suasana lain pada wacana, menyimpulkan, mengantisipasi bahkan kadang membingungkan. Peran katalisator menginformasikan sesuatu kisah yang dibawakan, sedang fungsi tetapnya adalah memainkan perasaan. Kemudian, fungsi Indeksikal, adalah keterangan yang menunjukan hubungan yang bersifat parametrikal bersifat kontinyu seperti tempo dalam musik yang melodinya secara horizontal bergerak monofoni. Dan berhubungan dengan pelaku atau informan berfungsi mengidentifikasi ruang dan waktu dari kisah yang dibawakan (Barthes, 1990: 245).

Contohnya: Bermain musik di Balai Adat untuk calempong, tindakan yang dapat berfungsi sebagai katalisator terhadap tindakan pokok "menghibur". Pada saat yang sama bisa menunjukan "indeks" suasana tertentu "gaya budaya tradisional, adat dan ritual". Makna dari narasi musik calempong sebagai makna informasi yang belum ditafsirkan, karena sifatnya hanya menginformasikan saja. Pemaknaan, terlihat pada indeks dan informan dari narasi musik.

\section{Level Aksi}

Level aksi membangun rasa alur naratif dalam musik untuk mengintegrasikan atau mengawinkan unit naratif yang telah diproduksi pada level sebelumnya supaya bisa dibawa pada level narasional dalam menemukan makna narasi musik. Struktur tindakannya: analisa karakter bunyi, tidak sebagai posisi utama untuk membentuk ranah deskripsi bunyi untuk memahami aksi. Tiga artikulasi utamanya adalah "hasrat", "komunikasi" dan, "perjuangan". Tindakannya adalah mendeskripsi dan mengklarifikasi karakter-karakter bunyi berdasarkan apa yang dimainkan. Model aktansial mengungkapkan peran struktural yang dilakukan dalam menceritakan sesuatu (Barthes. 1990: 258) ; misalnya dalam musik "komposer (pahlawan musik), pemusik (penolong komposer), objek (pencarian musik), pendengar musik (pendengar pahlawan dan penolongnya) dan pengirim cerita musik.Masing-masing peran ini memenuhi komponen integral dari cerita, naratif. Tanpa kontribusi masing-masing aktan, cerita musik tidak lengkap. Dengan demikian, aktan bukan hanya karakter dalam sebuah cerita musik, tetapi merupakan elemen keseluruhan struktur di mana narasi musik itu bergerak. Kunci level aksi adalah kategorikategori tata bahasa yang dimiliki personal. Namun kategori-kategori itu hanya dapat didefenisikan jika dihubungkan dengan wacana (Barthes, 1990: 260). Wacana adalah sebuah kalimat panjang yang tidak harus 
berupa kalimat-kalimat seperti halnya kalimat, dengan membuat spesifikasi tertentu adalah sebuah wacana pendek (Sunardi, 2002: 238). Karakter-karakter sebagai unit level aksi akan memperoleh maknanya bila diintegrasikan dengan level narasional.

Aktan juga dapat digambarkan sebagai pasangan oposisi biner, seperti komposer yang dipasangkan dengan komposisi musik, musisi yang dipasangkan dengan permainan musik, pertunjukan musik yang dipasangkan dengan pendengar pemusik. Hubungan aktansial sangat berguna dalam menghasilkan masalah dalam naratif, memberikan kontras, atau dalam mendefinisikan kekuatan antagonis dalam naratif. Namun, karakter yang sama dapat secara bersamaan memiliki aktan yang berbeda dalam hal urutan tindakan, peristiwa atau episode dalam cerita. Oleh karena itu, harus dibedakan dari peran konsisten karakter dalam cerita seperti model atau pola karakter. Konsep aktan dalam struktur naratif untuk menganggap setiap situasi sebagai unit cerita yang berdiri sendiri.

\section{Level Narasional}

Sebagaimana halnya dalam naratif, sebuah fungsi pertukaran besar yang dilihat sebagai objek, adalah dasar dari komunikasi: ada pemberi naratif dan penerima atau naratif (Barthes: 1990, 260-272). Demikian pula, naratif musik tidak dapat terjadi tanpa pemain musik dan pendengar (atau pembaca). Gagasan tentang pemberi naratif adalah: pertama, naratif berasal dari pribadi dalam pemahaman psikologis. Pribadi yang disebut sebagai pencipta musik yang berperan menuliskan naratif, tetapi pencipta musik sebagai dirinya tidak disebutkan dalam naratif, dia berada diluar narasi. Kedua, pemain musik sebagai yang maha tahu yang impersonal, tidak berwujud pribadi, tetapi kesadarannya dalam memainkan musik tradisi seperti superior, tanda pemain musik itu imanen dalam narasi musik. Ketiga, pandangan (Henery James, Satre) setiap karakter yang diciptakan oleh pemain musik menjadi pengirim naratif. Tokoh-tokoh naratif adalah pemain musik dan karakter sebagai orang yang nyata dan hidup dalam naratif. Artinya pencipta musik tidak dapat disamakan dengan pemain musik yang menyampaikan narasi dalam naratif. Pribadi yang berbicara dalam naratif bukanlah pribadi yang menulis dalam kehidupan nyata (Barthes, 1990: 261). Level narasional sarat dengan tanda-tanda narativitas yang mengintegrasikan level fungsi dan level aksi dalam narasional. Narasional sebagai satu kesatuan level yang berfungsi untuk mempertontonkan naratif. Dengan dipertontonkannya narasi, maka unit-unit dari level sebelumnya mencapai integrasi. Bentuk akhir naratif, mentransendensi "isi" dan "bentuk-bentuk naratif" yaitu "fungsi dan 
aksi” secara sempurna. Analisis naratif baru akan berhenti pada wacana yang lebih luas. Setiap naratif dibatasi atau bersifat independen terhadap"sistuasi naratif” yaitu seperangkat protokol yang dipakai sebagai sarana agar naratif bisa dikosumsi (Barthes, 1990: 267-268).

D. Simpulan

Masyarakat Unggan mengenal kuanta bunyi yang mempunyai dualisme bunyi sebagai partikel dan gelombang, mempunyai erat dengan filosofi masyarakat tentang sistem

\section{E. Daftar pustaka}

Alber, Jan, and Rüdiger Heinze, eds. 2011. Unnatural Narratives - Unnatural Narratology. Berlin: De Gruyter.

Alber, Jan, Stefan Iversen, Henrik Skov Nielsen, and Brian Richardson. 2012. "What Is Unnatural about Unnatural Narratology?: A Response to Monika Fludernik." Narrative 20 (3): 371-82. doi:10.1353/nar.2012.0020.

Alber, Jan, Stefan Iversen, Henrik Skov Nielson, and Brian Richardson. 2010. "Unnatural Narratives, Unnatural Narratology: Beyond Mimetic Models." Narrative 18 (2): 113-36.

Kramer, Lawrence.1991. Musical Narratology: A Theoretical Outline, Indiana Theory Review, Vol. 12 (SPRING and FALL 1991), pp. 141-162 kehidupan sehingga mengkontruksi pada sebuah makna keseimbangan dalam kehidupan. Uraian ini didukung oleh proses kontruksi bahwa terciptanya musik yang prosesnya sama dengan mimesis (bunyi sebagai representasi) dimana pelaku sebagai orang pertama meniru pendengaran bunyi dari dari dunia ide, selanjutnya adalah kepercayaan larangan membunyikan musik dimasa padi bercocok tanam padi, sedangkan yang ketiga adalah ruang komunikasi pencipta, musisi dan masyarakat.

Barthes, Roland. Image—Music_Text. Essays selected and translated by Stephen Heath. New York: Noonday, 1977.

Chatman, Seymour. 1988, On Deconstructing Narratology, Style, Vol.22, No.

1, Narrative Theory and Criticism (Spring 1988), pp.9-17.

Creswell. W. John. (2008). Narrative Research Designs dalam Educational Research, 3third edition, Pearson Education Intnc, USA.

Hayles, N. Katherine. 2002. Writing Machines. Cambridge, MA: MIT Press

Keraf, Gorys. 2001. Argumentasi dan Narasi. Jakarta: PT Gramedia Pustaka Utama.

McClary, Susan. 1997, The Impromptu That Trod on a Loaf: Or How Music Tells Stories, Narrative, Vol. 5, No. 1 (Jan., 1997), pp. 20-35 
Hery Budiawan, Fahmi Marh (Makna......)

Pp 27-36

Prince, Gerald. 1982. Narratology: The Form and Functioning of Narrative. Berlin: Mouton.

1992. Narrative as Theme: Studies in French Fiction. Lincoln: University of Nebraska Press.

2018.

Geographical

Narratology (special issue of Frontiers of

Narrative Studies, vol. 4, no. 2.

Pavel, Thomas. 2014. "Gerald Prince and Narrative Studies". Narrative. 22 (3): 298-303. doi:10.1353/nar.2014.0023.

Sunardi, St. 2002. Semiotika Negativa. Yogyakarta. Kanal 
